\title{
Characteristics of mesospheric gravity waves near the magnetic equator, Brazil, during the SpreadFEx campaign
}

\author{
M. J. Taylor ${ }^{1}$, P.-D. Pautet ${ }^{1}$, A. F. Medeiros ${ }^{2}$, R. Buriti ${ }^{2}$, J. Fechine ${ }^{2}$, D. C. Fritts ${ }^{3}$, S. L. Vadas ${ }^{3}$, H. Takahashi ${ }^{4}$, and \\ F. T. São Sabbas ${ }^{4}$ \\ ${ }^{1}$ Utah State University, Logan, UT, USA \\ ${ }^{2}$ Universidade Federal de Campina Grande, Campina Grande, Paraiba, Brazil \\ ${ }^{3}$ NorthWest Research Associates, CoRA Division, Boulder, CO, USA \\ ${ }^{4}$ Instituto Nacional de Pesquisas Espaciais (INPE), São José dos Campos, São Paulo, Brazil
}

Received: 6 May 2008 - Revised: 4 August 2008 - Accepted: 4 August 2008 - Published: 2 February 2009

\begin{abstract}
As part of the SpreadFEx campaign, coordinated optical and radio measurements were made from Brazil to investigate the occurrence and properties of equatorial Spread F, and to characterize the regional mesospheric gravity wave field. All-sky image measurements were made from two sites: Brasilia and Cariri located $\sim 10^{\circ} \mathrm{S}$ of the magnetic equator and separated by $\sim 1500 \mathrm{~km}$. In particular, the observations from Brasilia provided key data in relatively close proximity to expected convective sources of the gravity waves. High-quality image measurements of the mesospheric $\mathrm{OH}$ emission and the thermospheric OI $(630 \mathrm{~nm})$ emission were made during two consecutive new moon periods (22 September to 9 November 2005) providing extensive data on the occurrence and properties of F-region depletions and regional measurements of the dominant gravity wave characteristics at each site.

A total of 120 wave displays were observed, comprising 94 short-period events and 26 medium-scale gravity waves. The characteristics of the small-scale waves agreed well with previous gravity wave studies from Brazil and other sites. However, significant differences in the wave propagation headings indicate dissimilar source regions for the Brasilia and Cariri datasets. The observed medium-scale gravity wave events constitute an important new dataset to study their mesospheric properties at equatorial latitudes. These data exhibited similar propagation headings to the shortperiod events, suggesting they originated from the same source regions. Medium-scale waves are generally less susceptible to wind filtering effects and modeling studies utilizing these data have successfully identified localized regions
\end{abstract}

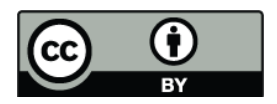

Correspondence to: M. J. Taylor (mtaylor@cc.usu.edu) of strong convection, mainly to the west of Brasilia, as their most likely sources (Vadas et al., 2009).

Keywords. Atmospheric composition and structure (Airglow and aurora) - Meteorology and atmospheric dynamics (Middle atmosphere dynamics; Waves and tides)

\section{Introduction}

Large-scale instabilities in the equatorial ionosphere are a well documented plasma phenomena that are know to cause severe regional blackouts in radio communications and to significantly disrupt GPS-based terrestrial navigation systems (e.g. Basu et al., 1999). These instabilities develop in the early evening hours, during the pre-reversal enhancement of the zonal electric field, when strong upward plasma drifts cause the F-region ionosphere to rise significantly (Heelis et al., 1974; Fejer et al., 1999). The resultant instabilities grow via the Rayleigh-Taylor mechanism which creates bubbles (or plumes) of plasma which can attain altitudes as high as $1500 \mathrm{~km}$ at the equator within a few hours (e.g. Woodman and La Hoz, 1976; Huang et al., 1993). The bubbles are readily observed in radar plots and appear as towering plumes extending from the lower ionosphere to the top side (e.g. Hysell and Burcham, 2002; de Paula and Hysell, 2004; Batista et al., 2004; Buriti et al., 2008). As the plumes raise in altitude their electron density signatures map down the magnetic flux tubes to lower latitudes where they are detected in the Fregion airglow emissions as field-aligned plasma depletions (Rishbeth, 1971; Batista et al., 1986; Abdu, 2001).

Of key importance to the understanding and eventual prediction of Spread $\mathrm{F}$ phenomena is the identification of potential seed mechanisms that can both initiate and help

Published by Copernicus Publications on behalf of the European Geosciences Union. 
accelerate the growth rate of the Rayleigh-Taylor instability (RTI). A number of theoretical and modeling studies have shown that atmospheric gravity waves may provide the essential seed forcing necessary to describe the observed bubble structures and their growth rates (Woodman and LaHoz, 1978; Rottger, 1981; Anderson et al., 1982; Valladares et al., 1983; Hanson et al., 1986; Hysell et al., 1990; Huang and Kelley, 1996a, b, c; Sekar and Kelley, 1998; Taylor et al., 1998). Gravity waves are generated primarily within the troposphere by severe weather disturbances, such as deep convection (e.g. Fritts and Alexander, 2003), as well as strong orographic forcing (e.g. Jiang et al., 2004). At tropical latitudes deep convection associated with severe storms is a copious source of a broad spectrum of gravity waves observed at mesospheric heights (e.g. Taylor et al., 1997; Nakamura et al., 2003; Medeiros et al., 2004; Suzuki et al., 2004; Pautet et al., 2005). These storms develop during the late afternoon and are well placed in space and time to provide seeding for the plume development over Brazil. The apparent correlation between ESF and enhanced equatorial convection provides additional support for this concept (McClure et al., 1998).

Gravity waves propagate energy and momentum upwards as they grow exponentially in amplitude and are known to play a key role in the MLT dynamics (e.g. Lindzen, 1981; Holton, 1983; Garcia and Solomon, 1985; Alexander and Holton, 1997; Fritts and Alexander, 2003). The waves are readily observed at mesospheric heights using the naturally occurring airglow emission. In particular all-sky imaging systems have been used to characterize the spectrum of the smaller-scale, shorter period waves (horizontal wavelength $\lambda_{x}<100 \mathrm{~km}$, observed period $\tau<30 \mathrm{~min}$ ), which are known to contribute significantly to momentum deposition at MLT heights (Fritts and Vincent, 1987). These data also provide important directional information helpful for identifying the sources of the waves (e.g. Taylor and Hapgood, 1988; Nakamura et al., 2003; Pautet et al., 2005). However, recent modeling studies have shown that a significant fraction of the convectively generated gravity waves of medium-scales ( $\lambda_{x}>100 \mathrm{~km}$ and observed periods of a few tens of minutes) are capable of propagating well into the lower thermosphere where they may directly act as seeds for the RTI (Vadas et al., 2009).

The SpreadFEx campaign was designed to investigate the potential and properties of convectively generated gravity waves as seeds for spread-F. The campaign was conducted in Brazil during the Austral spring 2005 and employed a broad range of available ground-based radar, ionosonde, allsky imaging, and GPS instrumentation, located at a number of selected sites in Brazil (see Campaign overview by Fritts et al., 2009). Here we summarize the results from the airglow imaging instrumentation used primarily to characterize the mesospheric gravity wave field near the magnetic equator, and to identify potential medium-scale wave events for detailed ray-tracing studies (as discussed by Vadas et al., 2009).

\section{Imaging instrumentation}

For the SpreadFEx campaign three high-quality imaging systems were used to quantify the occurrence and properties of mesospheric gravity waves and F-region depletions over Brazil using coordinated observations of several mesospheric and thermospheric nightglow emissions (see Fechine et al., 2009; Pautet et al., 2009; Vargas et al., 2009; Wrasse et al., 2009). In particular, all-sky ( $180^{\circ}$ field of view) image measurements provide two-dimensional information with high spatial and temporal resolutions over a large geographic area (e.g. Taylor et al., 1995, 1997a).

All three imagers utilized a sensitive back-thinned $1024 \times 1024$ pixel charge couple device (CCD) and were fitted with computer controlled filter wheels enabling sequential measurements of selected airglow emissions. Each imager was used to measure the mesospheric near infrared (NIR) hydroxyl $(\mathrm{OH})$ Meinel broad band emission $(710-930 \mathrm{~nm})$ and the OI $(630.0 \mathrm{~nm})$ thermospheric red-line emission. The nocturnal $\mathrm{OH}$ emission originates from a well-defined emissive layer centered at $\sim 87 \mathrm{~km}$ with half width 8-10 km (Baker and Stair, 1988), while thermospheric $630.0 \mathrm{~nm}$ is somewhat broader ( $\sim 50 \mathrm{~km}$ half-width) and resides at $\sim 250 \mathrm{~km}$ altitude, slightly below the F-region peak of electron density (e.g. Tinsley et al., 1973). Typical exposure times were $15 \mathrm{~s}$ for the bright $\mathrm{OH}$ emission bands and $90-120 \mathrm{~s}$ for the fainter OI $(630 \mathrm{~nm})$ line emission, with a cadence time of typically $2-2.5 \mathrm{~min}$. The data were $2 \times 2$ binned on the chip resulting in a zenith horizontal resolution of $\sim 0.5 \mathrm{~km}$ (e.g. Taylor et al., 1995). At Brasilia additional measurements of the OI $(557.7 \mathrm{~nm})$ line emission (peak altitude $\sim 96 \mathrm{~km}$ ) and a background sky measurement (at $572.5 \mathrm{~nm}$ ) for assessing sky clarity, were also occasionally made after 2 October.

\section{Coordinated observations}

The Utah State University (USU) multi-wavelength imaging system was deployed at a field site near Brasilia $\left(14.8^{\circ} \mathrm{S}\right.$, $\left.47.6^{\circ} \mathrm{W}\right)$. The two other imaging systems were located at permanent sites at Cariri $\left(7.4^{\circ} \mathrm{S}, 36.5^{\circ} \mathrm{W}\right)$ and Cachoeira Paulista $\left(22.7^{\circ} \mathrm{S}, 45.0^{\circ} \mathrm{W}\right)$, and were operated by the Universidade Federal de Campina Grande (UFCG) and INPE, respectively. Figure 1 illustrates the all-sky observing geometry. The location of these sites was chosen to provide good latitudinal and longitudinal sampling of the mesospheric gravity wave field while at the same time measuring the occurrence, spatial and temporal properties of thermospheric depletions induced by equatorial Spread-F. The USU camera at Fazenda Isabel (hereafter referred to as Brasilia) and the Cariri imager were both located at $\sim 10^{\circ} \mathrm{S}$ of the magnetic equator. This region was deemed of high interest as the observed bubble structure corresponded to equatorial plumes extending southward are a relatively common occurrence 


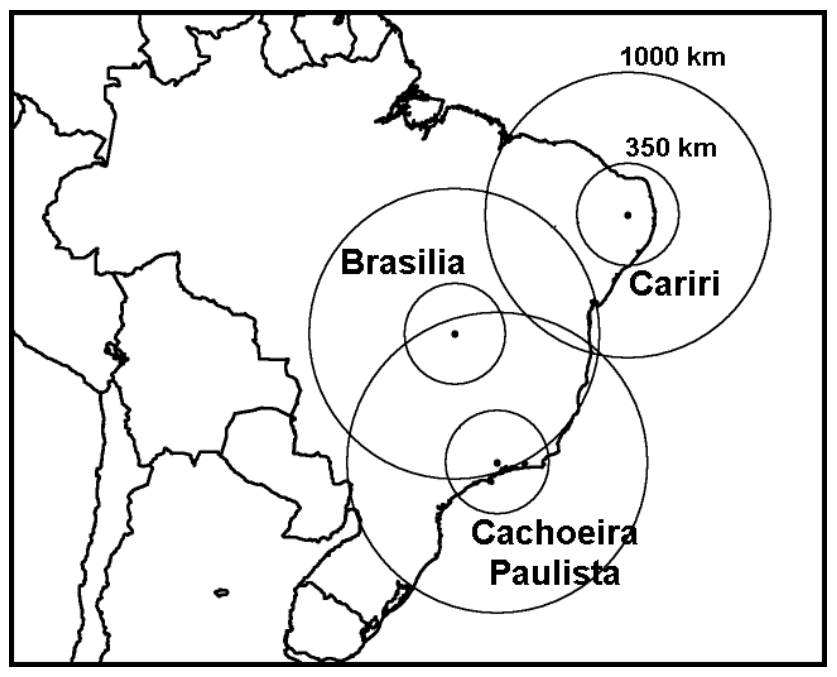

Fig. 1. Map of Brazil showing the location of the three camera sites; near Brasilia $\left(14.8^{\circ} \mathrm{S}, 47.6^{\circ} \mathrm{W}\right)$, at Cariri $\left(7.4^{\circ} \mathrm{S}, 36.5^{\circ} \mathrm{W}\right)$ and Cachoeira Paulista $\left(22.7^{\circ} \mathrm{S}, 45.0^{\circ} \mathrm{W}\right)$. The circles indicate the nominal fields of view of the all-sky imagers used for the mesospheric $\mathrm{OH}$ gravity wave measurements $(\sim 350 \mathrm{~km}$ radius $)$, assuming an emission height of $\sim 87 \mathrm{~km}$, and the thermospheric $630 \mathrm{~nm}$ depletion measurements ( $\sim 1000 \mathrm{~km}$ radius) for a peak emission altitude of $\sim 250 \mathrm{~km}$.

over Brazil during the springtime. Cachoeira Paulista is located at $15.8^{\circ} \mathrm{S}_{\mathrm{mag}}$ and provided sensitivity to higher altitude plumes, which are less common, but map to significantly lower latitudes. Importantly, these three sites also provided critical regional information on the mesospheric gravity wave field during the occurrence of Spread-F essential for our combined investigation of the potential for gravity wave seeding of ESF.

In particular, the measurements from Brasilia provided key data in relatively close proximity to expected convective sources of the gravity waves (located primarily to the West over the state of Mato Grosso), that may penetrate to thermospheric altitudes. The location of this field site was chosen especially for this campaign and observations were made for a limited $\sim 2$ month period during the spring 2005 spread-F season. In contrast, the Cariri and Cachoeira-Paulista sites were operated on a near-continuous basis by INPE in collaboration with the Universidade Federal de Campina Grande (for Cariri). Figure 1 shows the nominal fields of view of the all-sky imagers used for the mesospheric $\mathrm{OH}$ gravity wave measurements ( $\sim 350 \mathrm{~km}$ radius $)$, assuming an emission height of $\sim 87 \mathrm{~km}$, and the thermospheric $630 \mathrm{~nm}$ depletion measurements $(\sim 1000 \mathrm{~km}$ radius $)$ for a peak emission altitude of $\sim 250 \mathrm{~km}$. As the Brasilia and Cariri sites are separated by $\sim 1500 \mathrm{~km}$ the mesospheric data were more limited to regional gravity wave studies. However, the much larger fields of view of the thermospheric measurements gave significant overlap and provided good continuity for investigat-
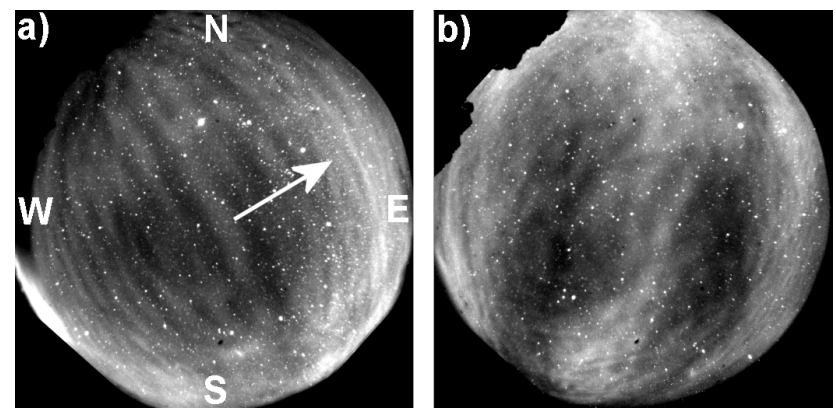

Fig. 2. Two examples of all-sky images showing short and mediumscale gravity wave structures in the mesospheric $\mathrm{OH}$ emission. The data were obtained from Brasilia on two consecutive nights (a) 30 September-1 October and (b) 1-2 October.

ing bubble dynamics (Pautet et al., 2009; Takahashi et al., 2009).

Coordinated image measurements were made during two consecutive moon down periods from 22 September to 9 October, and from 23 October to 9 November 2005. Unfortunately, poor weather conditions limited the Cachoeira Paulista measurements during the first observing period while the Brasilia measurements were often constrained by local thunderstorm activity during the latter part of the second observing period. The gravity wave measurements presented here utilize the Brasilia and Cariri data sets (total 17 nights from Brasilia and 19 from Cariri) when coincident high-quality image data were obtained on 8 nights, for quantifying the mesospheric gravity wave characteristics as well as the occurrence and properties of thermospheric bubbles.

Figure 2 shows two example all-sky images of gravity waves observed from Brasilia. These data are typical of the short-period wave events observed from both Brasilia and Cariri during the campaign. In (a), a well-developed, short-period, quasi-monochromatic gravity wave is evident in the $\mathrm{OH}$ emission extending across the entire field of view. This event was observed at $\sim 01: 30$ UT on the night of 30 September-1 October 2005, and exhibited a horizontal wavelength $\lambda_{x}=23 \pm 3 \mathrm{~km}$, an observed horizontal phase speed $v_{x}=32 \pm 5 \mathrm{~m} / \mathrm{s}$ and an observed period $\tau=12 \pm 2 \mathrm{~min}$. The wave pattern lasted for $2.25 \mathrm{~h}$ and progressed towards the ENE (azimuth $62 \pm 5^{\circ} \mathrm{N}$ ), as indicated by the arrow (note, the dark region to the NW is due to low elevation cloud).

Figure $2 b$ shows a different type of wave structure imaged on the following night (1-2 October). The small-scale waves are just as extensive but are much less coherent, and there is clear evidence for a larger scale gravity wave modulation in the image data (with a central bright crest and two adjacent troughs evident at this time), that is closely aligned with the smaller-scale waves. The short-period structures exhibited $\lambda_{x}=14 \pm 3 \mathrm{~km}, v_{x}=42 \pm 5 \mathrm{~m} / \mathrm{s}$ ( $\tau=5.6 \pm 2 \mathrm{~min}$ ) propagating almost due east $\left(89 \pm 5^{\circ}\right)$. In contrast, the larger-scale wave $\left(\lambda_{x}=159 \pm 3 \mathrm{~km}, v_{x}=50 \pm 5 \mathrm{~m} / \mathrm{s}\right)$, had an observed period of 

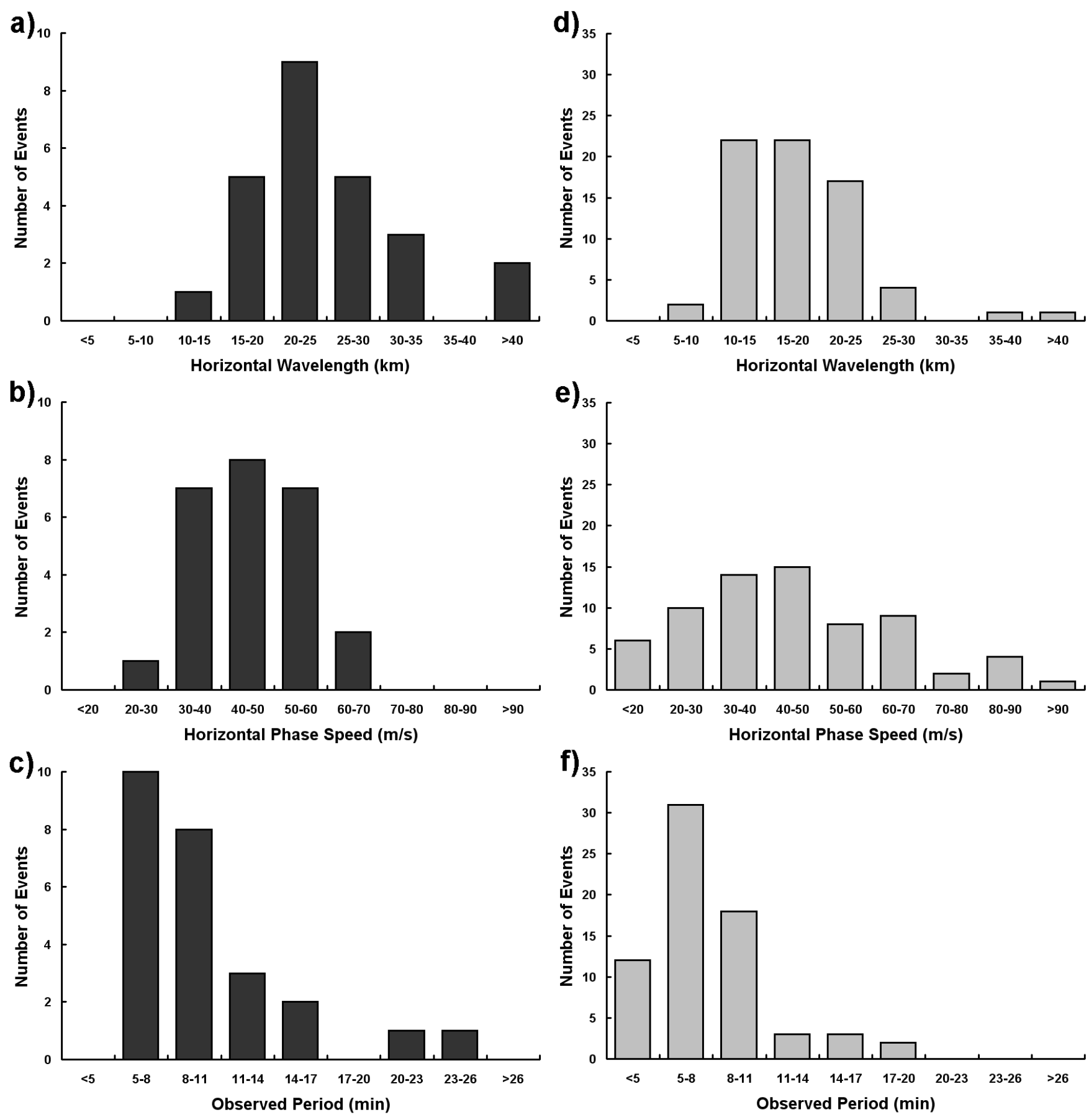

Brasilia

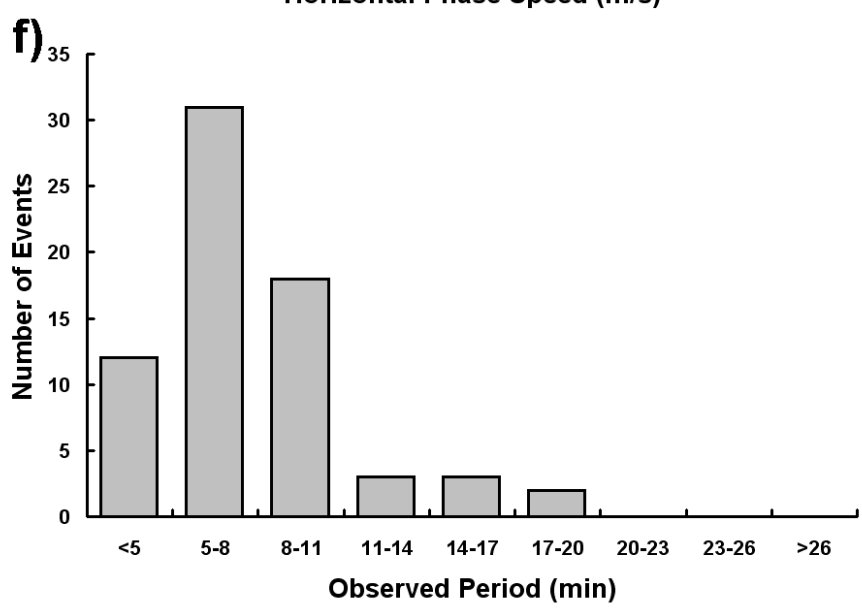

Cariri

Fig. 3. Histogram plots summarizing the characteristics of the short-period wave events observed from Brasilia (left) and Cariri (right). The uncertainties in the small-scale wave measurements are $\lambda_{x} \pm 3 \mathrm{~km}, v_{x} \pm 5 \mathrm{~m} / \mathrm{s}, \theta \pm 5^{\circ}$ and $\tau \pm 2 \mathrm{~min}$. Note the different scales.

$53 \pm 2 \min (\sim 10$ times that the smaller-scale events), as it progressed on a similar azimuth of $97 \pm 5^{\circ} \mathrm{N}$. Spectral analysis of this complex data set also revealed the presence of a second short-period wave progression more towards the SE (heading $138^{\circ} \mathrm{N}$ ) with $\lambda_{x}=28 \pm 3 \mathrm{~km}, v_{x}=33 \pm 5 \mathrm{~m} / \mathrm{s}$ and $\tau=14 \pm 2 \mathrm{~min}$.
The superposition of this wave motion with the 5.6 min wave event results in the more "mottled" appearance of the shortperiod wave events observed on this night.

In parallel with these mesospheric gravity wave measurements, observations of the $\mathrm{OI}(630 \mathrm{~nm})$ emission recorded the 
occurrence and characteristics of F-region depletion structures. Short-period gravity waves and spread-F depletions were observed on every clear night at Brasilia (total 17 nights). The $630 \mathrm{~nm}$ image data (not shown) revealed largescale, field-aligned depletion structures that drifted eastward during the course of the night with high initial values, around $120 \mathrm{~m} / \mathrm{s}$, in good agreement with available GPS measurements (J. S. Haase, personal communication, 2008), that reduced to zero by local midnight. The number of depletions and their horizontal scales and latitudinal extent varied considerably from night to night. These characteristics are typical of previous bubble measurements over Brazil (e.g. Taylor et al., 1997b; Pimenta et al., 2003; Arruda et al., 2006), and separate investigations comparing the scale-sizes of the mesospheric gravity waves and F-region depletions, and the longitudinal variability in the bubble characteristics are presented by Takahashi et al. (2009); Pautet et al. (2009).

\section{Image analysis and results}

Two analysis techniques were used to characterize the quasimonochromatic wave events imaged in the $\mathrm{OH}$ data from Brasilia and Cariri. One focused on quantifying the wave parameters of the smaller-scale $\left(\lambda_{x}<100 \mathrm{~km}\right)$, short observed period $(\tau<30 \mathrm{~min})$ waves that were evident within a single image as coherent wave patterns (e.g. Fig. 2a), while the second method utilized "Keograms" to identify and measure the properties of coherent, larger-scale waves, that are detectable over an extended period of time (typically several hours). In many prior airglow studies, the focus has usually been on quantifying the smaller-scale wave field (e.g. Taylor et al., 1997a; Medeiros et al., 2003; Ejiri et al., 2003). As the small-scale waves (often termed bands) are copious, they provide important 2-dimensional information on the dominant wave characteristics, pattern orientation and direction of motion helpful for source identification studies. However, for this investigation we also wish to identify longer-period wave events that are generally less susceptible to wind filtering, capable of propagating to higher altitudes (due to their higher phase speeds), and are therefore better suited for ray tracing studies to identify potential source regions (e.g. Vadas et al., 2009).

\subsection{Small-scale waves}

Figure 3 summarizes the small-scale wave measurements separately for Brasilia (left column) and Cariri (right column), in the form of histogram plots of horizontal wavelength $\left(\lambda_{x}\right)$, observed horizontal phase speed $\left(v_{x}\right)$ and inferred observed wave period $(\tau)$. The $\mathrm{OH}$ images were first calibrated using the known star background and then projected onto a regular $500 \times 500 \mathrm{~km}$ spatial grid using an assumed peak altitude of $87 \mathrm{~km}$. The horizontal parameters of the data $\left(\lambda_{x}, v_{x}, \tau\right)$ and propagation angle $(\theta)$, measured
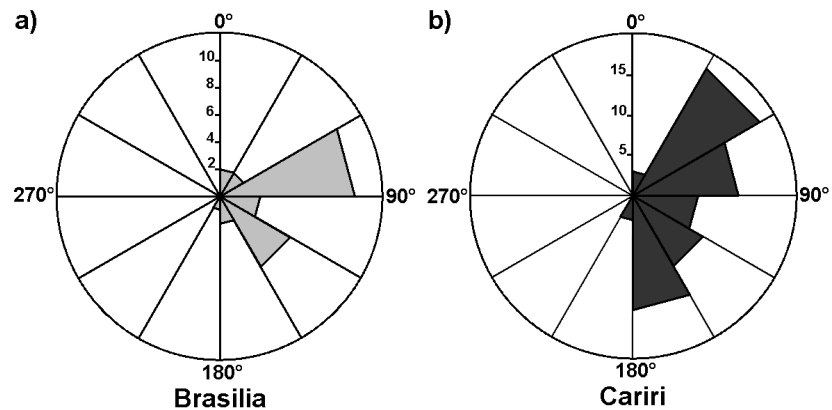

Fig. 4. Plots summarizing the number of wave events versus the direction of propagation (summed into $30^{\circ}$ bins) for Brasilia (left) and Cariri (right). Note the different scales.

from geographic North, were then determined using well established two-dimensional Fourier analysis techniques (Taylor and Garcia, 1995; Garcia et al., 1997; Coble et al., 1998). At Brasilia a total of 32 wave events were detected on 17 clear nights during the two observing periods. The observing conditions at Cariri were more favorable and 88 events were observed during 19 nights. Both sites exhibited a range of horizontal wavelengths with distributions between 10-25 km for Cariri and 15-30 km for Brasilia. Comparison of the observed phase speeds shows a broader range at Cariri than at Brasilia, but both data sets exhibit a strong preference for values around $30-60 \mathrm{~m} / \mathrm{s}$ with a range of typically $20-80 \mathrm{~m} / \mathrm{s}$. These resulted in relatively short observed wave periods clustered around $\sim 8-11 \mathrm{~min}$ (typical range $\sim 5-20 \mathrm{~min}$ ) at both sites. This said, in each case the Cariri data were found to have somewhat smaller median values $\left(\lambda_{x}=17.4 \mathrm{~km}, v_{x}=43.3 \mathrm{~m} / \mathrm{s}\right.$ and $\left.\tau=7.1 \mathrm{~min}\right)$ compared with Brasilia $\left(\lambda_{x}=23.2 \mathrm{~km}, v_{x}=50.5 \mathrm{~m} / \mathrm{s}\right.$ and $\left.\tau=9.0 \mathrm{~min}\right)$. These measurements are typical for small-scale mesospheric gravity waves as measured from a number of low-latitude sites in both hemispheres (e.g. Taylor et al., 1997a; Nakamura et al., 2003; Medeiros et al., 2003, 2004; Pautet et al., 2005).

Figure 4 compares the observed horizontal propagation directions for the short-period wave events from both sites. Due to the limited number of events, the data are divided into $30^{\circ}$ bins indicating the number of events as a function of azimuth. Both data sets show a strong preference for eastward wave propagation with only 4 events (3\%) exhibiting a small westward component of motion. Both sites also show significant meridional (N-S) components of motion. At Brasilia the wave headings are divided into two main directions $\sim \mathrm{E}$ and $\sim \mathrm{SE}$ (with almost equal preference), while at Cariri the range of wave headings is significantly larger $\sim \mathrm{NE}$ to $\mathrm{S}$ with the strongest preference for NE propagation. These results agree well with previous seasonal azimuthal studies in northeastern Brazil using the same instrumentation (e.g. Taylor et al., 1997a; Medeiros et al., 2003), and are discussed later. 


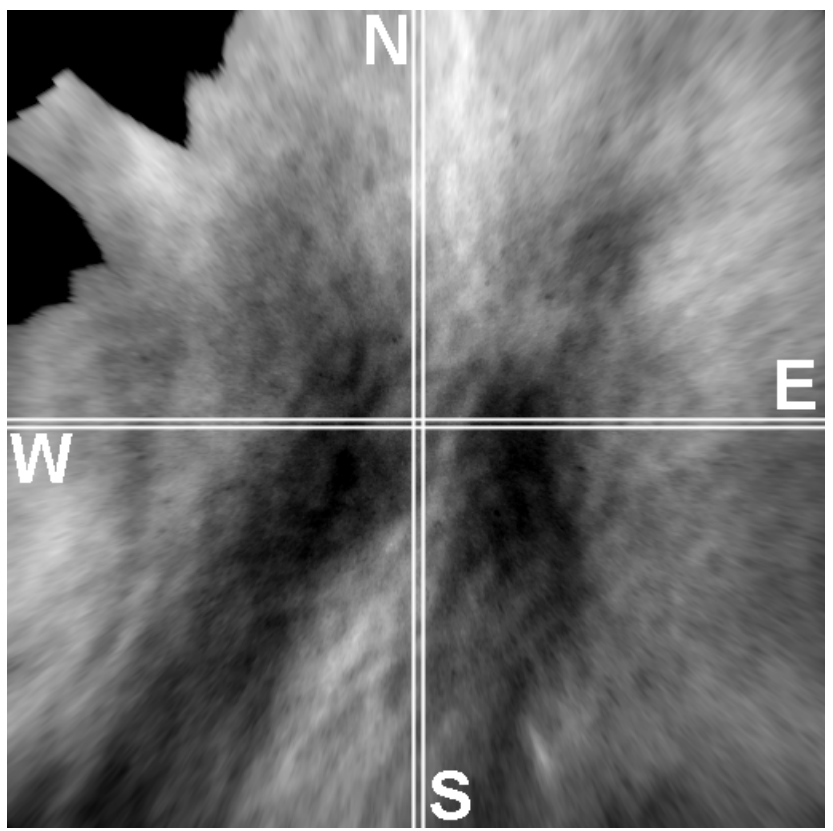

Fig. 5. Unwarped image of Fig. $2 \mathrm{~b}$ mapped on a $500 \times 500 \mathrm{~km}$ linear grid. The white lines delineate the rows and columns used to create the west-east and north-south Keograms, respectively.

\subsection{Medium-scale waves}

To investigate the larger-scale perturbations in the $\mathrm{OH}$ data, which have scale-sizes characteristic of medium-scale gravity waves, a sequence of images was used to create a Keogram. This technique was first employed to study the development and motion of large-scale auroral structures (e.g. Eather and Mende, 1981) but has been used on a number of occasions to summarize wave activity in airglow image data (e.g. Swenson et al., 2003). The initial data processing was the same as for the short-period waves, removing the stars and unwarping the image onto a square $500 \times 500 \mathrm{~km}$ grid. For example, Fig. 5 shows the processed image for the $\mathrm{OH}$ data of Fig. 2b (the dark region in the top left corner is due to trees). A Keogram is then made by taking the central column, or row, of each processed image and splicing the data together to create two time series showing the north-south, and east-west development, respectively. The white lines in Fig. 5 delineate the central row and columns used for creating the Keograms in this analysis.

Figure 6 compares the west-east Keograms for Cariri (a), and Brasilia (b), for the night of 1-2 October (including the data of Fig. 5). In each plot, the top border corresponds to east and the lower border to west, with zenith indicated by the horizontal dashed line. On this night, airglow data were obtained for about $10 \mathrm{~h}$ at each site. The Milky Way is not removed in our image processing and is visible in each plot as a bright curved band initially near the zenith, moving westward with time and exiting the cameras' field of view around

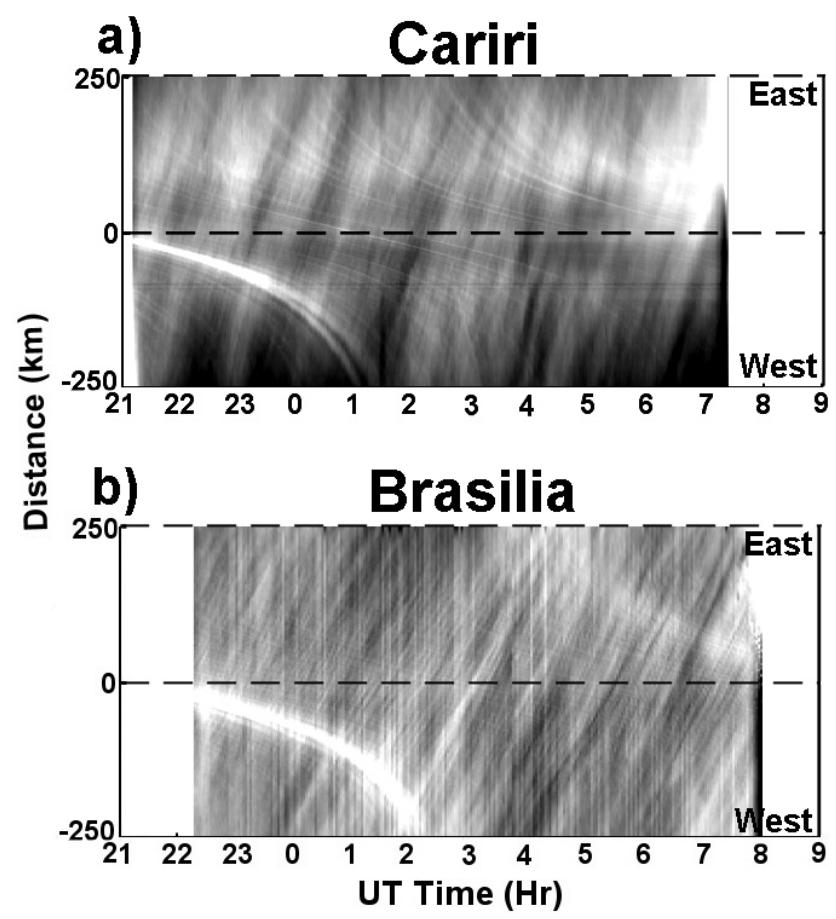

Fig. 6. Example west-east Keograms for (a) Cariri and (b) Brasilia obtained on the night of 1-2 October. The medium-scale gravity waves appear as coherent, tilted bands.

01:00-02:00 UT (later at Brasilia due to $\sim 12^{\circ}$ longitude difference between the two sites). Inspection of the Cariri data shows several coherent linear structures with a clear forward tilt. These are the signature of a medium-scale gravity wave that was most prominent from $\sim 21: 00$ to $02: 00 \mathrm{UT}$. The forward tilt indicates the direction of the zonal wave component (which in this case was eastward), while the angle of tilt yields its zonal speed. By combining together the N-S and E-W Keogram information the parameters of the mediumscale waves are readily determined. For this event at Cariri the medium-scale wave had a $\lambda_{x}$ of $265 \mathrm{~km}$, a $v_{x}$ of $69 \mathrm{~m} / \mathrm{s}$, an observed period of $64 \mathrm{~min}$ and progressed on a heading of $\sim 83^{\circ}$. For comparison, the Keogram data from Brasilia (plot b) show strong evidence of persistent short-period gravity wave activity progressing eastwards (indicated by the forward tilted fine scale structure), modulated by a larger-scale wave progressing in the same direction (as evident in Figs. $2 \mathrm{~b}$ and 5). This activity continued for most of the night.

In total, 6 medium-scale gravity wave events were observed from Brasilia and 20 from Cariri during the course of the campaign. The histogram plots of Fig. 7 summarize their main properties. In this case the Brasilia (dark) and Cariri (light shade) waves are plotted together to aid their comparison. The horizontal scale ranges from $\sim 100$ to $350 \mathrm{~km}$ with most events exhibiting wavelengths in the 100 $200 \mathrm{~km}$ range. The velocity data show a peak around 40$80 \mathrm{~m} / \mathrm{s}$ with no events $>100 \mathrm{~m} / \mathrm{s}$. This yielded an observed 
Table 1. Summary of medium-scale waves observed over Brasilia. The estimated uncertainties are $\pm 10 \%$ for the wave measurements.

\begin{tabular}{lccccccc}
\hline Date & Event \# & $\lambda_{x}(\mathrm{~km})$ & $v_{x}(\mathrm{~m} / \mathrm{s})$ & $\tau(\min )$ & $\theta\left({ }^{\circ} \mathrm{N}\right)$ & Start Time $(\mathrm{UT})$ & Duration $(\mathrm{h})$ \\
\hline 30 Sep & 1 & 145.1 & 73.3 & 33.9 & 84.3 & $02: 40$ & 1 \\
22 Oct & 2 & 71.4 & 57.7 & 20.6 & 90 & $23: 05$ & 2.75 \\
& 3 & 158.6 & 50.2 & 52.7 & 96.8 & $01: 03$ & 3.75 \\
& 4 & 64 & 70.4 & 15.2 & 145.9 & $00: 31$ & 1 \\
1 Oct & 5 & 61.4 & 28.7 & 35.7 & 143.4 & $23: 53$ & 3.25 \\
23 Oct & 6 & 148.3 & 27.4 & 90.2 & 136.3 & $01: 35$ & 1 \\
\hline
\end{tabular}

Table 2. Summary of medium-scale waves observed over Cariri. The estimated uncertainties are $\pm 10 \%$ for the wave measurements.

\begin{tabular}{lccccccc}
\hline Date & Event \# & $\lambda_{x}(\mathrm{~km})$ & $v_{x}(\mathrm{~m} / \mathrm{s})$ & $\tau(\min )$ & $\theta\left({ }^{\circ} \mathrm{N}\right)$ & Start Time $(\mathrm{UT})$ & Duration $(\mathrm{h})$ \\
\hline 23 Sep & 1 & 170.4 & 76.8 & 37 & 36.1 & $22: 00$ & 3 \\
& 2 & 91.5 & 56.4 & 27.8 & 36.7 & $21: 50$ & 1.2 \\
24 Sep & 3 & 119.9 & 52.8 & 37.9 & 38.7 & $22: 35$ & 2 \\
& 4 & 240.2 & 81.7 & 49 & 39.4 & $22: 00$ & 2 \\
25 Sep & 5 & 189.1 & 45 & 70 & 40.9 & $22: 00$ & 3 \\
28 Sep & 6 & 207.8 & 57.7 & 60 & 51.4 & $21: 30$ & 2.5 \\
29 Sep & 7 & 78.1 & 40.7 & 32 & 135.3 & $21: 00$ & 5.5 \\
30 Sep & 8 & 135 & 73.7 & 30.7 & 135 & $22: 45$ & 1.25 \\
& 9 & 220.4 & 69.3 & 53 & 138.6 & $22: 30$ & 2.5 \\
& 10 & 143 & 39 & 61 & 68 & $21: 10$ & 0.6 \\
1 Oct & 11 & 119.6 & 48 & 41 & 129 & $21: 45$ & 1.75 \\
& 12 & 265.1 & 69 & 64 & 83.2 & $21: 00$ & 5 \\
3 Oct & 13 & 208.9 & 71.1 & 49 & 82 & $21: 30$ & 3.5 \\
28 Oct & 14 & 184.8 & 79 & 39 & 43.8 & $22: 30$ & 1.5 \\
29 Oct & 15 & 177.9 & 64.5 & 46 & 88 & $21: 00$ & 5 \\
& 16 & 343.2 & 67.5 & 84.7 & 86.1 & $22: 00$ & 3 \\
30 Oct & 17 & 128.7 & 46.6 & 46 & 34.4 & $21: 30$ & 1.5 \\
31 Oct & 18 & 148.6 & 53.8 & 46 & 48 & $21: 00$ & 2 \\
1 Nov & 19 & 322.7 & 59.1 & 91 & 61.6 & $22: 00$ & 3 \\
2 Nov & 20 & 105.6 & 38.3 & 46 & 150 & $22: 00$ & 2 \\
\hline
\end{tabular}

period distribution extending from $\sim 20$ to $100 \mathrm{~min}$ with a broad peak centered around 20-60 min. For completeness the characteristics of each of these events are summarized in Table 1 (Brasilia) and Table 2 (Cariri).

\section{Discussion}

A primary observational goal of the SpreadFEx campaign was to characterize the mesospheric gravity wave field in close proximity to the magnetic equator where thermospheric bubbles form and grow. During the campaign we observed a total of 120 wave events, of which $22 \%$ were associated with medium-scale gravity waves. Together, these data provide essential information on the scale sizes, occurrence and directionality of mesospheric waves during the occurrence of Spread-F. The characteristics of the small-scale waves agree very well with previous gravity wave studies from north-eastern Brazil using the same instrumentation (e.g. Taylor et al., 1997a; Medeiros et al., 2004). However, our joint measurements of the medium-scale gravity waves constitute an important new dataset on their mesospheric properties at equatorial latitudes. Medium and large-scale gravity waves are usually observed as ionospheric electron density perturbations termed Traveling Ionospheric Disturbances (TID's). Their characteristics have been studied extensively using ionosonde and radar techniques (reviewed by Francis, 1975). Large-scale TIDs are often associated with high-latitude magnetic disturbances and can propagate large distances from their auroral source region (e.g. Davies and da Rosa, 1969), whereas medium scale TIDs exhibiting periods of several tens of minutes are prevalent at mid- and lowlatitudes and are thought to play a major role in the development of Spread-F (e.g. Kelley and Fukao, 1991).

To examine the nature of the medium-scale waves observed at both sites, Fig. 8 shows a log-log plot of their horizontal wavelengths as a function of their observed periods. The Cariri data are marked by open squares while the six 

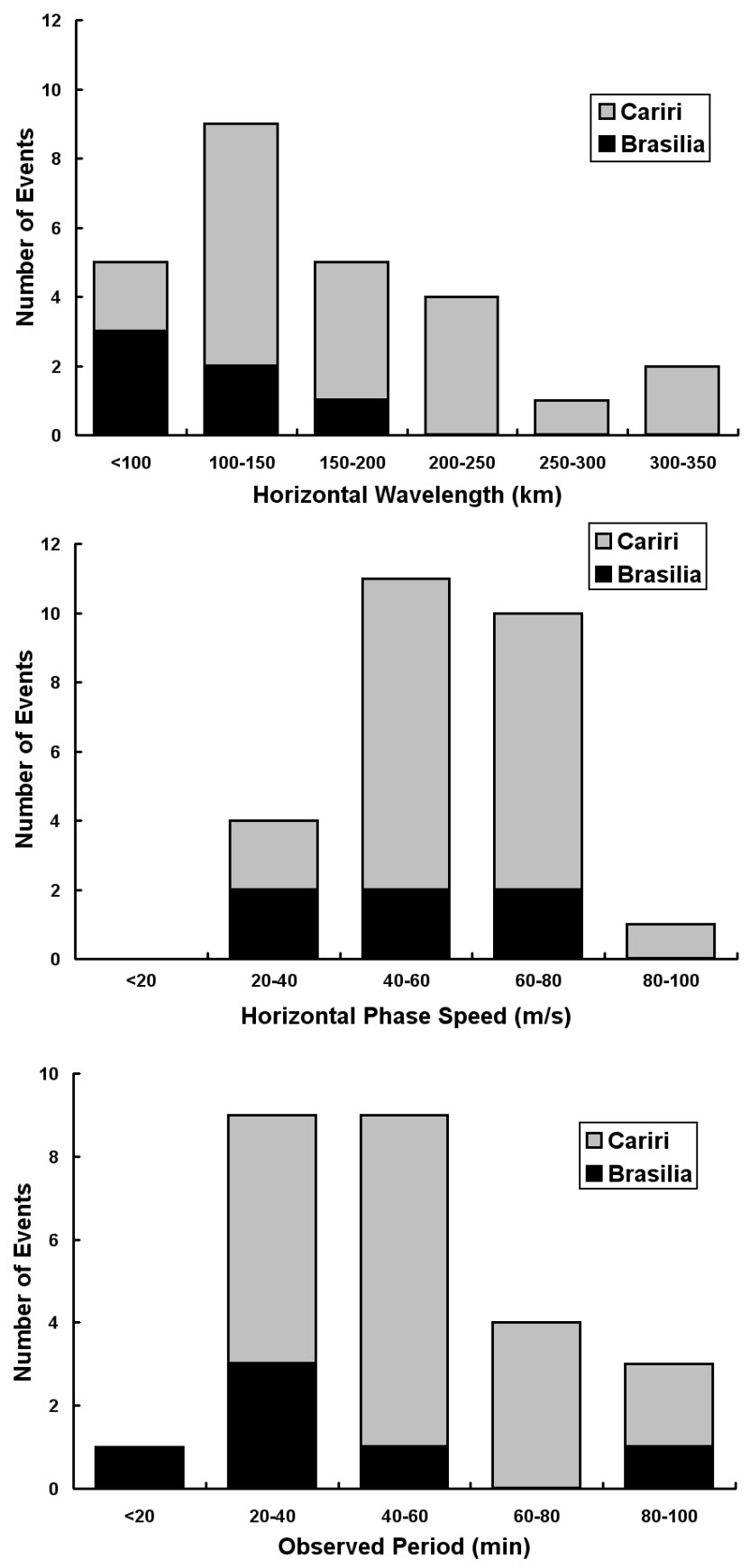

Fig. 7. Histograms showing the combined Brasilia and Cariri medium-scale wave characteristics.

Brasilia events are indicated by shaded circles. For comparison, the Brasilia small-scale wave events (solid circles) are also included on the figure. These three data sets overlap well and indicate a clear trend for increasing wavelength with observed wave period. In particular, the fitted trend line to these data $\left(R^{2} \sim 0.9\right)$, yields a power law of the form $\lambda_{h}=2.52 \tau^{1.05}$, which indicates that the dynamic range of the observed wave phase speeds is limited (factor of $\sim 4$ ) compared with the

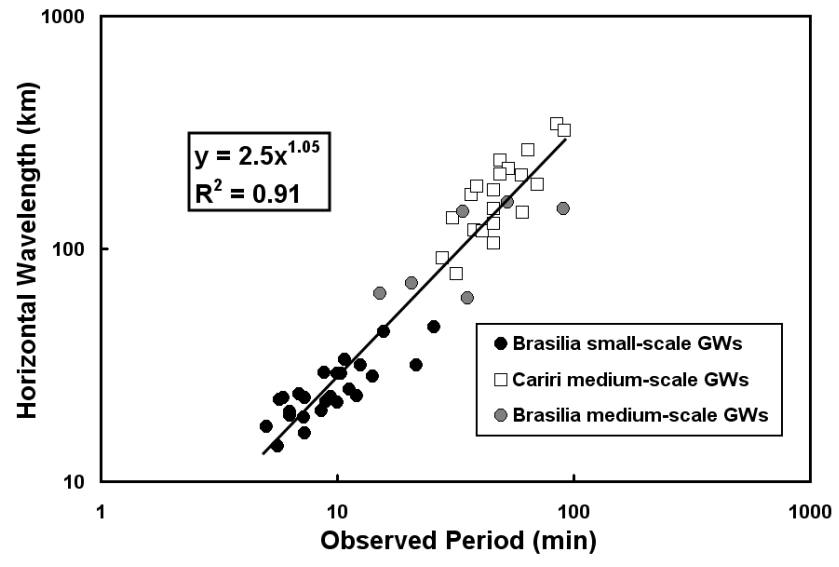

Fig. 8. Log-log plot showing the horizontal wavelength versus observed period. The data comprise the Brasilia and Cariri mediumscale waves and the Brasilia small-scale waves. The strait line shows the best fit to the data and agrees well with previous radar and optical studies of Reid (1986).

large dynamic ranges (factor of $\sim 20$ ) for the observed horizontal wavelengths and periods, and does not change significantly between the small and medium scale gravity waves reported in this study. This result compares very favorably with a previous, in-depth investigation of upper atmospheric gravity wave signatures using a compilation of optical and radar measurements by Reid (1986), who determined a trend of the form $\lambda_{h}=3.62 \tau^{1.06}$. Moreover, Taylor et al. (1997a) compared $\mathrm{OH}$ image measurements from the Guara campaign with Reid's compilation and determined a similar trend line of the form $\lambda_{h}=3.1 \tau^{1.06}$ for $\sim 50$ short-period wave events. This campaign was conducted in 1994 from Alcantara, Brazil $\left(2.6^{\circ} \mathrm{S}, 44.2^{\circ} \mathrm{W}\right), \sim 1300 \mathrm{~km}$ to the northwest of Cariri, under similar seasonal conditions (September-October 1994). Thus, the wave events derived from the Keogram analysis are consistent with those expected from medium-scale gravity waves, and they significantly extend the usual range of gravity wave measurements by imagers.

To investigate the origin of these waves, Fig. 9 plots separately their observed phase speed versus propagation direction for Brasilia and Cariri. Comparison of these plots with the data of Fig. 4 immediately shows that the medium and small-scale waves observed at each site both exhibited the same azimuthal distributions. At Cariri the medium and small-scale waves all progressed eastwards but with a strong preference for NE motion. A similar result was obtained by Taylor et al. (1997a), using OH airglow measurements during the Guara campaign, over 10 years prior to the SpreadFEx campaign, suggesting that the observed eastward velocity distribution is a seasonally recurrent phenomenon.

In contrast, the velocity distribution at Brasilia indicates two distinct preferential directions of motion: one due east and the other approximately SE. Due to the large separation of these two sites $(\sim 1500 \mathrm{~km})$ it is not expected that freely 

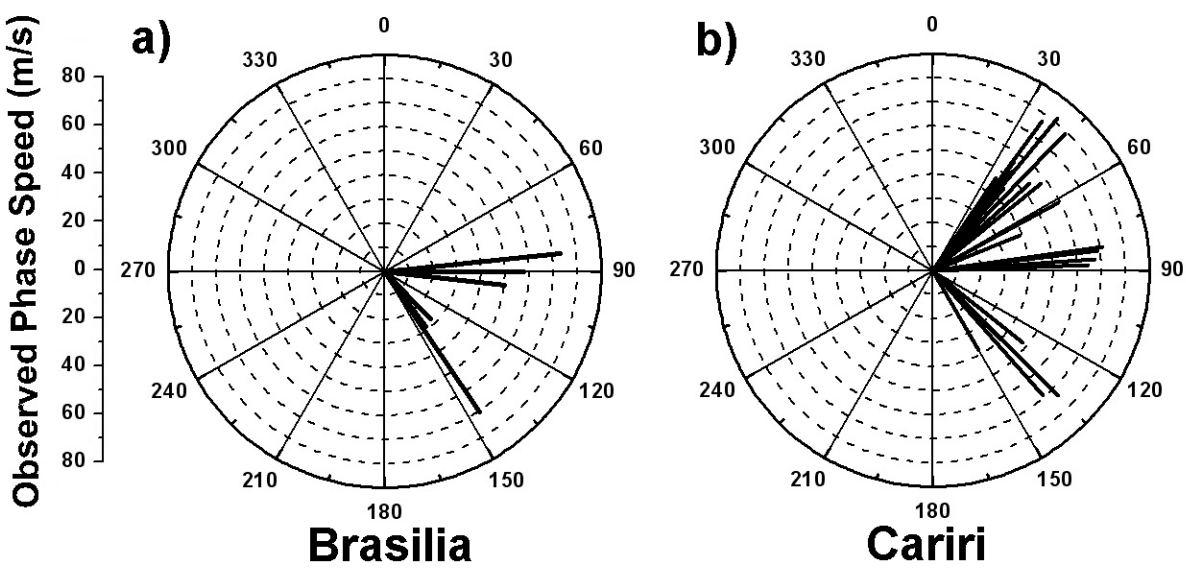

Fig. 9. Velocity plots showing the azimuthal distribution of the medium-scale waves. Note the similarity with the small-scale wave data of Fig. 4.

propagating short-period gravity waves observed at each site would have a common origin (e.g. Hines, 1967). Indeed, in an investigation of short-period mesospheric waves observed from two well-separated sites $(\sim 660 \mathrm{~km})$ in Japan, Taylor et al. (1998) determined that the majority of the wave events ( $\sim 75 \%$ ) exhibited quite dissimilar characteristics, suggesting a preponderance for more localized wave motions and sources. More recently, Ejiri et al. (2003) have also shown significant differences in gravity wave characteristics observed from sites separated by $\sim 1000 \mathrm{~km}$. Closer inspection of the medium-scale waves (Table 1) and the small-scale wave data reveals that southeastward wave propagation dominated during the first observing period (22 September to 9 October), while eastward wave motions prevailed during the second observing phase (22 October to 9 November). This suggests that the mesosphere over Brasilia was strongly influenced by local wave sources.

Vadas et al. (2009) have investigated the sources of the medium-scale waves observed from Brasilia using ray tracing techniques. These waves are less susceptible to wind filtering effects than the many of the smaller-scale waves, due to their larger scale sizes and somewhat higher phase speeds (typically $40-80 \mathrm{~m} / \mathrm{s}$ ), and are therefore better suited for ray tracing studies to identify potential source regions. As there is considerable uncertainty in the background stratospheric and mesospheric wind field during the campaign, Vadas et al. utilized balloon sounding, meteor radar data, and TIMEGCM model wind data (and no wind conditions), to estimate the geographic location of the source region for each of the six medium-scale wave events. They concluded that strong thunderstorm convection to the west of Brasilia was most likely the source of these waves. This result is illustrated in Fig. 10 which shows a GOES infrared satellite image of Brazil at 20:45 UT on 1 October. The location of Cariri and Brasilia are marked. On this night, medium-scale waves were observed at both sites (as discussed earlier in Fig. 6). The

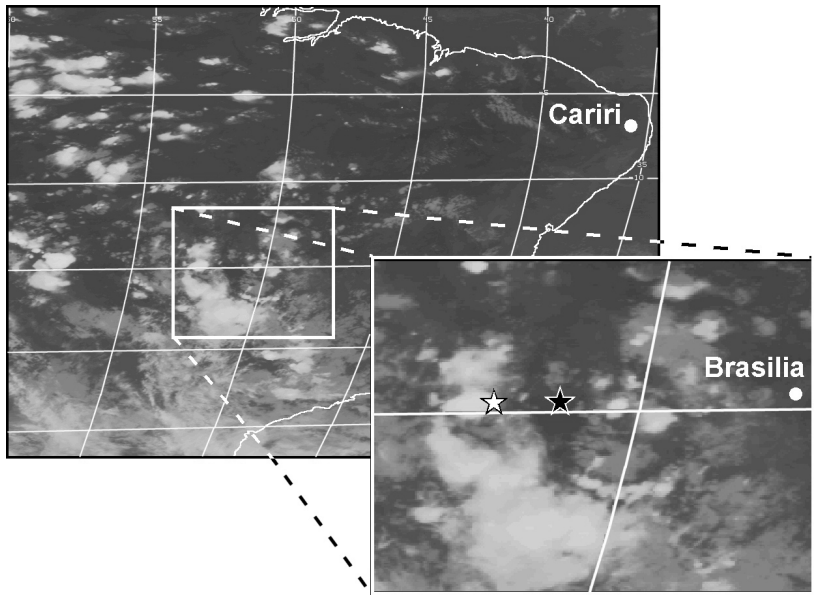

Fig. 10. GOES infrared satellite image showing the location of the convection over Brazil on the night of 01 October at 20:45 UT. Note the absence of convection in the vicinity of Cariri. The stars in the enlargement show the results of ray tracing of the event \#2 from Table 1 (Vadas et al., 2009).

satellite image shows considerable convective storm activity generally to the west of Brasilia at ranges of a few hundred $\mathrm{km}$. The insert shows a magnified image of this region. In particular, the star marks the ray-traced location of the source of the medium scale wave observed from Brasilia on this night (event 2 in Table 1). The two computed locations are for the model winds (black star), and for a "no wind" condition (white star). The close proximity of the traced positions to strong localized convection that occurred $\sim 1-2 \mathrm{~h}$ prior to the observed wave event are consistent with this storm being the most-likely source of the medium-scale waves. See Vadas et al. (2009) for further details.

In contrast, the satellite data show no significant convective activity in the vicinity of Cariri on this night, yet the Keogram data of Fig. 6a clearly indicate a well-developed 
medium-scale wave event (accompanied by smaller scale waves). Wrasse et al. (2009) have also utilized ray tracing techniques to investigate potential sources for some of the Cariri medium-scale waves. They determined that these waves originated near regions of intense upward air motion producing vertical instability, as derived from NCEP reanalysis data. Thus, while strong thunderstorms were most probably the source of many of the gravity waves observed from Brasilia, it appears that convection was not a prominent source for the wave events observed well to the east at Cariri.

\section{Summary}

The SpreadFEx campaign was designed to help quantify the role of gravity waves in the seeding and formation of equatorial F-region bubbles and associated Spread-F phenomena. As part of this program all-sky image measurements of mesospheric gravity waves were made successfully from two sites in Brazil located $\sim 10^{\circ} \mathrm{S}$ of the magnetic equator. The large separation of these sites, $\sim 1500 \mathrm{~km}$, enabled regional measurements of the gravity wave field while at the same time providing continuous, spatially overlapping data on the occurrence and properties of F-region depletion structures. The characteristics of the short-period wave events at each site were found to be consistent with prior image measurements, from Brazil and from other, low and mid-latitude sites. However, significant differences in the wave propagation headings at each site indicate dissimilar source regions for the two data sets.

Novel wave measurements using Keograms have been used to determine the properties of 26 medium-scale gravity waves detected in the $\mathrm{OH}$ emission at $\sim 87 \mathrm{~km}$ altitude. At each site the medium-scale waves exhibited similar propagation headings to the short-period events, suggesting common origins. These wave are less susceptible to wind filtering effects than many of the smaller-scale, lower phase speed waves, and modeling studies using these data have been used successfully to identify localized regions of strong convection, mainly to the west of Brasilia, as their most likely sources. Forward modeling studies (not discussed herein) have also shown that some of the medium-scale, convectively generated gravity waves were capable of propagating well into the lower thermosphere where they may have acted directly as seeds for the Rayleigh-Taylor instability development (Vadas et al., 2009).

Acknowledgements. We wish to thank E. Bataglin, manager of the Fazenda Isabel Ranch, for hosting our field measurements near Brasilia. The SpreadFEx program was supported by a NASA Living with a Star Program under contracts NNH04CC67C and NAS502036 (Principal Investigator: D. C. Fritts). The USU all-sky image measurements and data analyses were supported by a subcontract with Colorado Research Associates (a division of North West Research Associates). The optical measurements at Cariri Airglow Observatory were supported by INPE and the Universidade Fed- eral de Campina Grande, to whom we are most grateful. We acknowledge the use of GOES satellite imagery and thank Pete Stamus (CoRA) for his assistance in their analysis. We thank T. Nakamura and anonymous reviewer for their comments.

Topical Editor U.-P. Hoppe thanks T. Nakamura and another anonymous referee for their help in evaluating this paper.

\section{References}

Abdu, M. A.: Outstanding problems in the equatorial ionospherethermosphere electrodynamics relevant to spread F, J. Atmos. Terr. Phys., 63, 869-884, 2001.

Alexander, M. J. and Holton, J. R.: A model study of zonal forcing in the equatorial stratosphere by convectively induced gravity waves, J. Atmos. Sci., 54, 408-419, 1997.

Anderson, D. N., Richmond, A. D., Balsley, B. B., Roble, R. G., Biondi, M. A., and Sipler, D. P.: In situ generation of gravity waves as a possible seeding mechanism for equatorial spread-F, Geophys. Res. Lett., 9, 789-792, 1982.

Arruda, D. C. S., Sobral, J. H. A., Abdu, M. A., Castilho, V. M., Takahashi, H., Medeiros, A. F., and Buriti, R. A.: Theoritical and experimental zonal drift velocities of the ionospheric plasma bubbles over the Brazilian region, Adv. Space Res., 38, 26102614, 2006.

Baker, D. J. and Stair Jr., A. T.: Rocket measurements of the altitude distributions of the hydroxyl airglow, Phys. Scr., 37, 611-622, 1988.

Basu, S., Groves, K. M., Quinn, J. M., and Doherty, P.: A comparison of TEC fluctuation and scintillations at Ascension Island, J. Atmos. Sol. Terr. Phys., 61, 1219-1226, 1999.

Batista, I. S., Abdu, M. A., and Bittencourt, J. A.: Equatorial Fregion vertical plasma drifts: seasonal and longitudinal asymmetries in the American sector, J. Geophys. Res., 91, 12055 12 064, 1986.

Batista, P. P., Clemesha, B. R., Tokumoto, A. S., and Lima, L. M.: Structure of the mean winds and tides in the meteor region over Cachoeira Paulista, Brazil $\left(22.7^{\circ} \mathrm{S}, 45^{\circ} \mathrm{W}\right)$ and its comparison with models, J. Atmos. Solar-Terr. Phys., 66(6-9), 623-636, 2004.

Buriti, R. A., Hocking, W. K., Batista, P. P., Medeiros, A. F., and Clemesha, B. R.: Observations of equatorial mesospheric winds over Cariri $\left(7.4^{\circ} \mathrm{S}\right)$ by a meteor radar and comparison with existing models, Ann. Geophys., 26, 485-497, 2008, http://www.ann-geophys.net/26/485/2008/.

Coble, M. R., Papen, G. C., and Gardner, C. S.: Computing two dimensional unambiguous horizontal wavenumber spectra from OH airglow images, IEEE Trans. Geosci. Remote Sens., 36(2), 368-382, 1998.

Davies, M. J. and Da Rosa, A. V.: Travelling ionospheric disturbances originating in the auroral oval during polar substorms, J. Geophys. Res., 74, 5721-5735, 1969.

de Paula, E. R. and Hysell, D. L.: The São Luis $30 \mathrm{MHz}$ coherent scatter ionospheric radar: system description and initial results, Radio Sci., 39, RS1014, doi:10.1029/2003RS002914, 2004.

Eather, R. H. and Mende, S. B.: Dayside aurora studies with a keogram camera, Antarct. J. U.S., 15, 203-211, 1981.

Ejiri, M. K., Shiokawa, K., Ogawa, T., Igarashi, K., Nakamura, T., and Tsuda, T.: Statistical study of short-period gravity waves in 
$\mathrm{OH}$ and OI nightglow images at two separated sites, J. Geophys. Res., 108(D21), 4679, doi:10.1029/2002JD002795, 2003.

Fechine, J., Wrasse, C. M., Takahashi, H., Medeiros, A. F., Batista, P. P., Clemesha, B. R., Lima, L. M., Fritts, D. C., Laughman, B., Taylor, M. J., Pautet, P.-D., Mlynczak, M. G., and Russell, J. M.: Mesospheric bore event during SpreadFEx campaign, Ann. Geophys., in review, 2009.

Fejer, B. G., Scherliess, L., and de Paula, E. R.: Effects of the vertical plasma drift velocity on the generation and evolution of equatorial spread F, J. Geophys. Res., 104, 19 859-19869, 1999.

Francis, S. H.: Global propagation of atmospheric gravity waves: A review, J. Atmos. Terr. Phys., 37, 1011-1054, 1975.

Fritts, D. C. and Alexander, M. J.: Gravity wave dynamics and effects in the middle atmosphere, Rev. Geophys., 41(1), 1003, doi:10.1029/2001RG000106, 2003.

Fritts, D. C. and Vincent, R. A.: Mesospheric momentum flux studies at Adelaide, Australia: observations and a gravity wave-tidal interaction model, J. Atmos. Sci., 44, 605-619, 1987.

Fritts, D. C., Abdu, M. A., Batista, B. R., Batista, I. S., Batista, P. P., Buriti, R., Clemesha, B. R., Dautermann, T., de Paula, E. R., Fechine, B. J., Fejer, B. G., Gobbi, D., Haase, J. S., Kamalabadi, F., Kherani, E. A., Laughman, B., Lima, P. P., Liu, H.-L., Medeiros, A. F., Pautet, P.-D., Riggin, D. M., Rodrigues, F. S., São Sabbas, F. T., Sobral, J. H. A., Stamus, P., Takahashi, H., Taylor, M. J., Vadas, S. L., Vargas, F., and Wrasse, C. M.: Overview and summary of the Spread-F Experiment (SpreadFEx), Ann. Geophys., in review, 2009.

Garcia, R. R. and Solomon, S.: The effects of breaking gravity waves on the dynamics and chemical composition of the mesosphere and lower thermosphere, J. Geophys. Res., 90, 38503868, 1985.

Garcia, F. J., Taylor, M. J., and Kelley, M. C.: Two-dimensional spectral analysis of mesospheric airglow image data, Appl. Optics, 36(29), 7374-7385, 1997.

Hanson, W. B., Cragin, B. L., and Dennis, A.: The effect of vertical drift on the equatorial F-region stability, J. Atmos. Terr. Phys., 48, 205-212, 1986.

Heelis, R. A., Kendall, P. C., Moffet, R. J., Windle, D. W., and Rishbeth, H.: Electrical coupling of the $\mathrm{E}$ and $\mathrm{F}$ regions and its effect on the F region drifts and winds, Planet. Space Sci., 22, 743-756, 1974.

Hines, C. O.: On the nature of traveling ionospheric disturbances launched by low-altitude nuclear explosion, J. Geophys. Res., 72, 1877-1882, 1967.

Holton, J. R.: The influence of gravity wave breaking on the circulation of the middle atmosphere, J. Atmos. Sci., 40, 2497-2507, 1983.

Huang, C. S., Kelley, M. C., and Hysell, D. L.: Nonlinear RayleighTaylor instabilities, atmospheric gravity waves, and equatorial spread-F, J. Geophys. Res., 98, 15 631-15 642, 1993.

Huang, C. S. and Kelley, M. C.: Nonlinear evolution of equatorial spread-F. 1. On the plasma instabilities and spatial resonance associated with gravity wave seeding, J. Geophys. Res., 101, 283292, 1996a.

Huang, C. S. and Kelley, M. C.: Nonlinear evolution of equatorial spread-F. 2. Gravity seeding of Rayleigh-Taylor instability, J. Geophys. Res., 101, 293-302, 1996b.

Huang, C. S. and Kelley, M. C.: Nonlinear evolution of equatorial spread-F. 4. Gravity velocity shear, and day-to-day variability, J.
Geophys. Res., 101, 24 523-24 532, 1996c.

Hysell, D. L., Kelley, M. C., Swartz, W. E., and Woodman, R. F.: Seeding and layering of equatorial spread-F, J. Geophys. Res., 95, 17 253-17 260, 1990.

Hysell, D. L. and Burcham, J. D.: Long term studies of equatorial spread $\mathrm{F}$ using the JULIA radar at Jicamarca, J. Atmos. Sol. Terr. Phys., 64, 1531-1543, 2002.

Jiang, J. H., Eckermann, S. D., Wu, D. L., and Ma, J.: A search for mountain waves in MLS stratospheric limb radiances from the winter northern hemisphere: data analysis and global mountain wave modeling, J. Geophys. Res., 109(D3), D03107, doi:10.1029/2003JD003974, 2004.

Kelley, M. C. and Fukao, S.: Turbulent upwelling of the midlatitude ionosphere. 2. Theoretical framework, J. Geophys. Res., 96(A3), 3747-3753, 1991.

Lindzen, R. S.: Turbulence and stress owing to gravity wave and tidal breakdown, J. Geophys. Res., 86, 9707-9714, 1981.

McClure, J. P., Singh, S., Bamgboye, D. K., Johnson, F. S., and Kil, H.: Occurrence of equatorial $F$ region irregularities: Evidence for tropospheric seeding, J. Geophys. Res., 103, 29 119-29 135, 1998.

Medeiros, A. F., Taylor, M. J., Takahashi, H., Batista, P. P., and Gobbi, D.: An investigation of gravity wave activity in the low-latitude upper mesosphere: Propagation direction and wind filtering, J. Geophys. Res., 108(D14), 4411, doi:10.1029/2002JD002593, 2003.

Medeiros, A. F., Buriti, R. A., Machado, E. A., Taylor, M. J., Takahashi, H., Batista, P. P., and Gobbi, D.: Comparison of gravity wave activity observed by airglow imaging from two different latitudes in Brazil, J. Atmos. Sol. Terr. Phys., 66, 647-654, 2004.

Nakamura, T., Aono, T., Tsuda, T., Admiranto, A. G., Achmad, E., and Suranto: Mesospheric gravity waves over a tropical convective region observed by $\mathrm{OH}$ airglow imaging in Indonesia, Geophys. Res. Lett., 30(17), 1882, doi:10.1029/2003GL017619, 2003.

Pautet, P. D., Taylor, M. J., Liu, A. Z., and Swenson, G. R.: Climatology of short-period gravity waves observed over northern Australia during the Darwin Area Wave Experiment (DAWEX) and their dominant source regions, J. Geophys. Res., 110, D03S90, doi:10.1029/2004JD004954, 2005.

Pautet, P.-D., Taylor, M. J., Chapagain, N. P., Takahashi, H., Medeiros, A. F., São Sabbas, F. T., and Fritts, D. C.: Simultaneous Observations of Equatorial F-Region Plasma Depletions over Brazil During the Spread F Experiment (SpreadFEx), Ann. Geophys., in review, 2009.

Pimenta, A. A., Bittencourt, J. A., Fagundès, P. R., Sahai, Y., Buriti, R. A., Takahashi, H., and Taylor, M. J.: Ionospheric plasma bubble zonal drifts over the tropical region: a study using OI $630 \mathrm{~nm}$ emission all-sky images, J. Atmos. Terr. Phys., 65, 1117-1126, 2003.

Reid, I. M.: Gravity wave motion in the upper middle atmosphere (60-110 km), J. Atmos. Terr. Phys., 48, 1057-1072, 1986.

Reinisch, B. W., Scali, J. L., Haines, D. M.: Ionospheric drift measurements with ionosondes, Ann. Geophys., 41(5-6), 695-702, 1998.

Rishbeth, H.: Polarization fields produced by winds in the equatorial F region, Planet. Space Sci., 19, 357-369, 1971.

Rottger, J.: Equatorial spread-F by electric fields and atmospheric gravity waves generated by thunderstorms, J. Atmos. Terr. Phys., 
43, 453-462, 1981.

Sekar, R. and Kelley, M. C.: On the combined effects of vertical shear and zonal electric field patterns on nonlinear equatorial spread F evolution, J. Geophys. Res., 103, 20 735-20 747, 1998.

Suzuki, S., Shiokawa, K., Otsuka, Y., Ogawa, T., and Wilkinson, P.: Statistical characteristics of gravity waves observed by an allsky imager at Darwin, Australia, J. Geophys. Res., 109, D20S07, doi:10.1029/2003JD004336, 2004.

Swenson, G. R., Liu, A. Z., Li, F., and Tang, J.: High frequency atmospheric gravity wave damping in the mesosphere, Adv. Space Res., 32(5), 785-793, 2003.

Takahashi, H., Taylor, M. J., Pautet, P.-D., Medeiros, A. F., Gobbi, D., Wrasse, C. M., Fechine, J., Abdu, M. A., Batista, I. S., de Paula, E. R., Sobral, J. H. A., Aruda, D., and Fritts, D. C.: Simultaneous observation of ionospheric plasma bubbles and mesospheric gravity waves during the SpreadFEx campaign, Ann. Geophys., in press, 2009.

Taylor, M. J. and Hapgood, M. A.: Identification of a thunderstorm as a source of short period $(<1 \mathrm{hr})$ gravity waves in the upper atmospheric night glow emissions, Planet. Space Sci., 36, 975985, 1988.

Taylor, M. J. and Garcia, F. J.: A two-dimensional spectral analysis of short period gravity waves imaged in the OI $(557.7 \mathrm{~nm})$ and nearinfrared $\mathrm{OH}$ nightglow emissions over Arecibo, Puerto Rico, Geophys. Res. Lett., 22, 2473-2476, 1995.

Taylor, M. J., Bishop, M. B., and Taylor, V.: All-sky measurements of short period waves imaged in the OI $(557.7 \mathrm{~nm}), \mathrm{Na}$ $(589.2 \mathrm{~nm})$ and near infrared $\mathrm{OH}$ and $\mathrm{O} 2(0,1)$ nightglow emissions during the ALOHA-93 campaign, Geophys. Res. Lett., 22, 2833-2836, 1995.

Taylor, M. J., Pendleton Jr., W. R., Clark, S., Takahashi, H., Gobbi, D., and Goldberg, R. A.: Image measurements of short-period gravity waves at equatorial latitudes, J. Geophys. Res., 102, 26283-26 299, 1997a.
Taylor, M. J., Eccles, J. V., LaBelle, J., and Sobral, J. H. A.: High resolution OI $(630 \mathrm{~nm})$ image measurements of F-region depletion drifts during the Guára campaign, Geophys. Res. Lett., 24, 1699-1702, 1997b.

Taylor, M. J., Jahn, J.-M., Fukao, S., and Saito, A.: Possible evidence of gravity wave coupling into the mid-latitude $F$ region ionosphere during the SEEK campaign, Geophys. Res. Lett., 25, 1801-1804, 1998.

Tinsley, B. A., Christensen, A. B., Bittencourt, J., Gouveia, H., Angreji, P. D., and Takahashi, H.: Excitation of oxygen permitted line emissions in the tropical nightglow, J. Geophys. Res., 78, 1174-1186, 1973.

Vadas, S. L., Taylor, M. J., Pautet, P.-D., Stamus, P. A., Fritts, D. C., Liu, H.-L., São Sabbas, F. T., Rampinelli, V. T., Batista, P., and Takahashi, H.: Convection: the likely source of the medium-scale gravity waves observed in the $\mathrm{OH}$ airglow layer near Brasilia, Brazil, during the SpreadFEx campaign, Ann. Geophys., 27, 231-259, 2009, http://www.ann-geophys.net/27/231/2009/.

Valladares, C. E., Hanson, W. B., McClure, J. P., and Cragin, B. L.: Bottomside sinusoidal irregularities in the equatorial $\mathrm{F}$ region, J. Geophys. Res., 88, 8025-8042, 1983.

Vargas, F., Gobbi, D., and Takahashi, H.: Gravity wave amplitudes and momentum fluxes inferred from $\mathrm{OH}$ airglow intensities and meteor radar winds during SpreadFEx, Ann. Geophys., in review, 2009.

Woodman, R. F. and La Hoz, C.: Radar observations of F region equatorial irregularities, J. Geophys. Res., 81, 5447-5466, 1976.

Wrasse, C. M., Takahashi, H., Medeiros, A. F., and Bageston, J. V.: Mesospheric gravity wave observations during the SpreadFEx campaign: Evidence of tropospheric sources, Ann. Geophys., in review, 2009. 